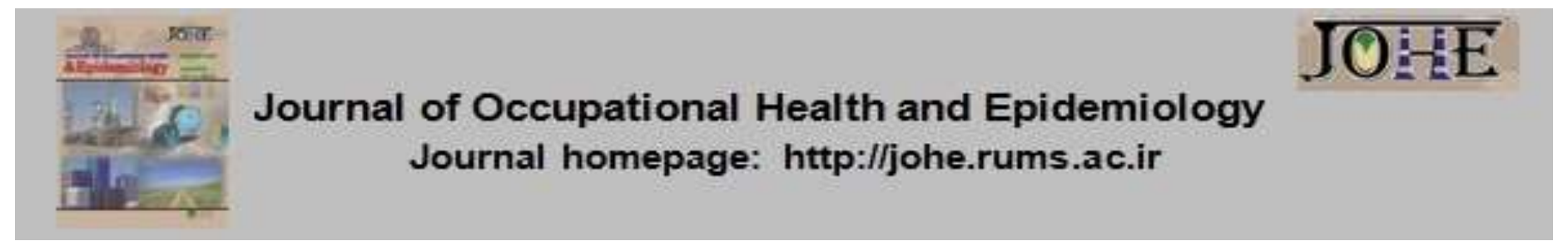

\title{
Job Alienation and Its Impact on Teachers' Job Performance and Quality of Life in Shahroud County, Iran (2017-2018)
}

\author{
Masoumeh Falah Nodehi * \\ - Instructor, Educational Sciences and Psychology, Payame Noor University, Tehran, Iran.
}

\section{Article Info}

* Corresponding author:

Masoumeh Falah Nodehi,

E-mail:

m_fallah@pnu.ac.ir

\section{Article history}

Received: Dec 2019

Accepted: May 2020

10.29252/johe.9.1.61

Print ISSN: 2251-8096 Online ISSN: 2252-0902

Peer review under responsibility of Journal of Occupational Health and Epidemiology
Citation: Falah Nodehi M. Job Alienation and Its Impact on Teachers' Job Performance and

Quality of Life in Shahroud County, Iran (2017-2018). JOHE 2020; 9(1):61-7.

\begin{abstract}
Background: An effective learning procedure is depended on the usefulness of the education system. In this context, education policymakers focus on recognizing factors influencing student learning outcomes. This study aims to investigate job alienation in high school teachers and its impacts on their job performance and quality of life.

Materials and Methods: This descriptive study was conducted on teachers $(N=110)$ employed in the high schools of Shahroud County in the academic year of 2017-2018, who were selected by the random sampling method. For the purpose of data collection, Persian versions of the Work Alienation Scale (WAS), the Quality of Life Questionnaire (QOLQ), and the Job Performance (JP) Questionnaire were utilized. Data were analyzed using SPSS V21.0 and linear regression was used to predict variables.

Results: According to the results, the coefficient of determination (R2) was 0.191 indicating that job alienation accounted for $19.1 \%$ of the variance in job performance. Based on the results, job alienation $(P<0.01, \beta=-0.437)$ led to significant negative job performance. In addition, the coefficient of determination (R2) was 0.115 indicating that job alienation accounted for $11.5 \%$ of the variance in the quality of life. Based on the results, job alienation $(\beta=-0.339, P<0.01)$ significantly predicted the quality of life.

Conclusions: It is concluded that the working conditions of teachers should be improved constantly, taking into account the findings of this research and the factors identified as effective in causing work alienation.
\end{abstract}

Keywords: Job Performance, Quality of Life, Teachers.

\section{Introduction}

An effective teaching and learning environment has a direct relationship with students' subjective behavior and relationships [1]. Knowing factors considered important to teachers is very helpful in creating school contexts that enhance teacher commitment and preventing them from leaving schools. By analyzing things most rewarding and important to teachers, one could have a better understanding of their attitudes towards school reforms and intervention programs [2]. The Job Characteristics Theory (JCT) [3-4] was one of the primary organizational theories that integrated meaningful work and specified the conditions required for people of high motivation and performance at work. The model proposed job dimensions, including internal work motivation, quality job performance, job satisfaction, and low presence. According to JCT, staff have a positive impact when they perform well. This positive impact is highly motivational and offers positive feedbacks on high-quality performance, job satisfaction, and other useful work outcomes [5]. The effectiveness or performance of an individual is closely linked to many personal and environmental factors in everyday work life. While positive factors improve productivity by disclosing positive experiences in individuals, negative factors decrease the quality of life and efficacy in 
them. Job alienation is one of the factors affecting an individual's job performance and quality of life. As part of daily life, it affects people physically, behaviorally, and mentally, with this being reflected in the state of mind as well as health. Thus, it is important to raise people's awareness of factors, such as occupational alienation affecting their morale and effectiveness [6].

Hoy et al defined job alienation as "the reflection of one's feelings created by the despair of working conditions at work" [7]. In a study, job alienation was defined as the result of the inability of an organization to provide conditions and environments, such as independence, responsibility, social interaction, as well as the selfrealization of the value of individuals as human beings [8]. McKinley and Marceau reaffirmed the importance of defining the alienation framework [9]. They concluded that "the classic notion of alienation could be based on previous valuable works that provide a new coherent explanation for the workplace. Job alienation as well as its impacts on job and family circumstances are the main subjects to be discussed."

Job alienation arouses the feelings of meaninglessness, aimlessness, and social isolation. All these consequences have negative impacts on teacher performance [10]. Various types of research have been conducted to examine the effects of job alienation. For example, Akar found out that teachers' perceptions of worklife quality had a negative impact on teacher burnout and school alienation [11]. Data from 227 staff at a manufacturing company in the UK demonstrated that the absence of person-job fit led to alienation in the workplace, psychological fatigue, and low levels of well-being as its subsequences [12-13].

In their study, Tajvaran and Seif showed that the quality of work-life variables had an indirect negative effect on job alienation through conflict mediation, organizational commitment, and job involvement. In addition, the variable of conflict had an indirect positive effect on job alienation through the mediation of organizational commitment [14]. The results of the analysis in a study showed that job alienation negatively correlated with organizational health, and that job alienation accounted for $21.5 \%$ of the total variance in organizational health [15]. According to another study, job alienation has a negative direct effect on self-esteem, thereby having a negative effect on job performance [16]. According to the findings of a study, work alienation has an impact on both job outcomes and work-family enrichment. In particular, work meaninglessness is relevant to both work outcomes and family life [17].
The studies mentioned above considered reasons for job alienation and its consequences from different perspectives. This study aims to examine the impact of job alienation on teachers' performance and quality of life, which is an innovation in this field. In addition, there has been no research conducted on high school teachers in Shahroud County in this field, which shows the importance of this research. The present study could help managers maintain and better understand human resources to take appropriate measures so as to obtain teacher job satisfaction and prevent a sense of job alienation in providing quality services to students. Thus, this study aims to examine job alienation in high school teachers as well as its impact on their job performance and quality of life.

\section{Materials and Methods}

This study is descriptive-correlational in nature. The statistical population of this study included high school teachers in Shahroud County, who were surveyed in the academic year of 2017-2018. The inclusion criteria consisted of presenting written informed consent forms for taking part in the study, having more than 5 years of teaching experience, and being at least 25 years old; in contrast, the exclusion criteria consisted of presenting incomplete questionnaires and showing dissatisfaction with participation in this study. It is worth noting that before administering the test, the purpose of this research was explained to the participants. All Helsinki ethics requirements, including the participants' freedom in leaving the exam whenever they wished and the confidentiality of their information were met. To this end, they were assured that their information would be confidential, and they were informed that they did not need to mention their names. Due to the incompleteness of some questionnaires, 110 out of 141 questionnaires were analyzed. To distribute the questionnaires, 141 individuals were selected using the limited community sampling formula as follows:

$n=\frac{N Z_{\frac{2}{2}}^{\frac{2}{2}} P(1-P)}{\theta^{2}(N-1)+\frac{Z_{x}^{2}}{2} P(1-P)}=\frac{300 \times 1.96^{2} \times .50 \times .50}{.06^{2} \times(299)+1.96^{2} \times .50 \times .50} \cong 141$

$\mathrm{N}$ : The community size

$\mathrm{n}$ : The sample size

$\mathrm{Za} / 2$ : The estimated value of 1.96 with a confidence coefficient of $95 \%$

e: The accuracy of the estimation or differentiation of the actual ratio of a trait in the population with researcher estimation for that trait in the population considered at 0.06 in the present study

q: The proportion of failures in the sample being $50 \%$; q $=1-p$

p: A $50 \%$ success rate 
Work Alienation Scale (WAS): The work alienation scale was developed by Mottaz and included 21 items. All items use a 5-point Likert scale ranging from 1 to 5 , indicating strongly disagree to strongly agree unless stated otherwise [18]. Work alienation has the three subscales of powerlessness, meaninglessness, and selfendangerment, with each of which having 7 items. The sample items included "My daily tasks are largely determined by others" and "I have a great deal of freedom in performing my daily tasks" (R). Work meaninglessness was measured using a 7item scale. The sample items were "I am sometimes unsure to completely understand the purpose of what I am doing", "I often wonder what the importance of my job really is", and "My work is really important and worthwhile" (R). The minimum and maximum scores the respondents would receive in this questionnaire were 21 and 147, respectively. To calculate the overall score of the questionnaire, the scores obtained for each of the questions would be summed, with the extent of the respondents' work alienation considered. Obviously, the higher the score was, the greater the person's responsibility for alienation would be, and vice versa. The Cronbach's alpha for the senses of helplessness, nonsense, and selfloathing was $0.73,0.86$, and 0.77 , respectively [18]. The structural validity indices of this questionnaire were calculated as AGFI $=0.80, \mathrm{GFI}$ $=0.84$, and RMSEA $=0.88$ [19], and the Cronbach's alpha was 0.77 .

Job performance (JP): Peterson and Byron developed a self-report questionnaire with 15 items rated by a 4-point Likert scale. It was validated in previous studies on Iranian workers and used to measure job performance $[20,21]$. This questionnaire has four questions with the options of "very poor (rarely)", "poor (sometimes)," "good (often)", and "excellent (always)". For each of the aforementioned options, points $0,1,2$, and 3 were given, respectively. Therefore, scores for each subject ranged from 0 to 45 . In the current study, the Cronbach's alpha was 0.85 .

Quality of Life Questionnaire (QOLQ): Wier and Sherbourne designed this self-report questionnaire generally used to evaluate the quality of life and well-being [22]. This questionnaire has 36 expressions and 8 areas of bodily function, physical role, bodily pain, common health, vitality, social functioning, emotional role, and mental health. In each area, a subject's score ranges from 0 to 100 , and a higher score suggests a higher quality of life [22]. The questionnaire is self-report, with the score in each item ranging from 1 to 5 , which includes the options of not at all, low, medium, and high. The physical health range of the questionnaire totaled $3,4,10,15,16,17,18$, and 18. The sum of scores for the psychological domain of the quality of life was $26,19,11,7,6$, and 5 . The scores for the social relations summary questions were 22, 21, and 20. In addition, the environment scope and living conditions scored 8 , $9,12,13,14,23,24$, and 25 . It should be noted that questions 3,4 , and 25 are reversed. To interpret this scale correctly, the short version must be converted into a long version. Next, the quality of life in each domain must be interpreted from 0 to 100 as shown below, with the minimum score for each domain being 4 . The sum of raw scores for each domain was multiplied by 4 . The internal consistency coefficients of the eight subscales in the Iranian population were reported from 0.70 to 0.85 [23]. In addition, Cronbach's alpha for the quality of life questionnaire in this research was 0.87.

SPSS V21.0 was used for data analysis. Linear regression was used to predict job performance and the quality of life using the variable of job alienation tendency. The results of this test are presented below.

\section{Results}

Regarding the respondents' educational qualifications, as Table 1 shows, about $62.72 \%$ of the respondents held an MA, and $37.27 \%$ of them held a BA. With respect to the respondents' gender, according to the results, $68.18 \%$ and $31.81 \%$ of them were female and male, respectively. In terms of marital status, according to the results, $69.09 \%$ and $30.90 \%$ of them were married and single, respectively.

Table 1. Demographic variables of teachers in Shahroud County, Iran, 2017-2018

\begin{tabular}{cccr}
\hline Variable & Group & Frequency & Percentage \\
\hline \multirow{2}{*}{ Sex } & Male & 35 & 31.81 \\
\cline { 2 - 4 } & Female & 75 & 68.18 \\
\hline \multirow{2}{*}{ Education } & BA & 41 & 37.27 \\
\cline { 2 - 4 } & MA & 69 & 62.72 \\
\hline \multirow{2}{*}{ Marriage } & Married & 76 & 69.09 \\
\cline { 2 - 4 } & Single & 34 & 30.90 \\
\end{tabular}


Table 2 shows descriptive statistics for the mean and standard deviation along with the correlation coefficients between the variables of job alienation, job performance, and the quality of life. According to the results, the correlation coefficient between job alienation and job performance was -0.437 . In addition, the correlation coefficient between job alienation and the quality of life was -0.339 , which was significant at the alpha level of 0.01 ( $p<0.01)$. The negative coefficients indicate an inverse relationship between job alienation and job performance as well as the quality of life. Therefore, people with higher job alienation have a better job performance and a lower quality of life.

Table 2. Statistical description and correlations between research variables among teachers of Shahroud County, Iran, 2017-2018

\begin{tabular}{|c|c|c|c|c|c|}
\hline & Mean & Std. Deviation & 1 & 2 & 3 \\
\hline Job alienation & 58.89 & 9.503 & 1 & & \\
\hline Job performance & 43.97 & 8.130 & $-0.437^{\star \star}$ & 1 & \\
\hline Quality of life & 72.65 & 10.149 & $-0.339^{\star *}$ & $0.257^{* *}$ & 1 \\
\hline
\end{tabular}

**. Correlation is significant at the level of 0.01 (2-tailed).

Table 3 presents the results of regression analysis for predicting job performance through the variable of job alienation. The coefficient of determination (R-squared) was 0.191 indicating that job alienation accounted for $19.1 \%$ of the variance in job performance. Based on the results, job alienation $(P<0.01, \quad \beta=-0.437)$ predicted significant negative job performance. It is concluded that upon an increase in job alienation in individuals, their job performance will decrease.

Table 3. Regression analysis for predicting job performance through the variable of job alienation among teachers of Shahroud County, Iran, 2017-2018

\begin{tabular}{|c|c|c|c|c|c|c|c|c|c|}
\hline & \multicolumn{2}{|c|}{$\begin{array}{l}\text { Unstandardized } \\
\text { Coefficients }\end{array}$} & \multirow{2}{*}{$\begin{array}{c}\begin{array}{c}\text { Standardize } \\
\text { d } \\
\text { Coefficients }\end{array} \\
\text { Beta }\end{array}$} & \multirow[t]{2}{*}{$\mathbf{T}$} & \multirow[t]{2}{*}{ Sig } & \multirow[t]{2}{*}{$\mathbf{R}$} & \multirow{2}{*}{$\begin{array}{l}\text { R- } \\
\text { Squar } \\
\text { ed }\end{array}$} & \multirow[t]{2}{*}{$\mathbf{F}$} & \multirow[t]{2}{*}{ Sig } \\
\hline & B & Std. Error & & & & & & & \\
\hline Constant & 65.969 & 2.393 & - & 27.567 & 0.001 & 0.437 & 0.191 & 86.677 & 0.001 \\
\hline $\begin{array}{c}\text { Job } \\
\text { alienation }\end{array}$ & -0.374 & 0.040 & -0.437 & -9.310 & 0.001 & - & - & - & - \\
\hline
\end{tabular}

Table 4 presents regression analysis results for predicting the quality of life through the variable of job alienation. The coefficient of determination (Rsquared) is 0.115 indicating that job alienation accounted for $11.5 \%$ of the variance in the quality of life. Based on the results, job alienation $(\beta=-$ $0.339, P<0.01$ ) significantly predicted the quality of life. It is concluded that people with higher job alienation have a lower quality of life.

Table 4. Regression analysis for predicting the quality of life through the variable of job alienation among teachers of Shahroud County, Iran, 2017-2018

\begin{tabular}{|c|c|c|c|c|c|c|c|c|c|}
\hline & \multicolumn{2}{|c|}{$\begin{array}{l}\text { Unstandardized } \\
\text { Coefficients }\end{array}$} & \multirow{2}{*}{$\begin{array}{c}\begin{array}{c}\text { Standardize } \\
\text { d } \\
\text { Coefficients }\end{array} \\
\text { Beta }\end{array}$} & \multirow[t]{2}{*}{$\mathbf{T}$} & \multirow[t]{2}{*}{ Sig } & \multirow[t]{2}{*}{$\mathbf{R}$} & \multirow{2}{*}{$\begin{array}{l}\text { R- } \\
\text { Squar } \\
\text { ed }\end{array}$} & \multirow[t]{2}{*}{$\mathbf{F}$} & \multirow[t]{2}{*}{ Sig } \\
\hline & B & Std. Error & & & & & & & \\
\hline Constant & 93.993 & 3.124 & & 30.089 & 0.001 & 0.339 & 0.115 & 47.884 & 0.001 \\
\hline $\begin{array}{c}\text { Job } \\
\text { alienation }\end{array}$ & -0.362 & 0.052 & -0.339 & -6.920 & 0.001 & & & & \\
\hline
\end{tabular}

\section{Discussion}

This article aimed to examine the effects of job alienation in teachers on their job performance and quality of life. According to the findings of this study, the groups of teachers with low job alienation had the highest mean of job performance. In contrast, the teachers with the highest job alienation had the lowest mean of job performance. As the Table shows, the groups of teachers with average job alienation had the highest mean of the quality of life. In contrast, the teachers with the highest job alienation had the lowest mean of the quality of life. According to the results, job alienation did not affect teachers' job performance and quality of life.

The first conclusion drawn is that job alienation could be a useful notion when studying teachers' experiences of their work, especially given the strong effects of high job alienation on different 
outcomes. This is consistent with the results implying that when teachers feel alienated from their work, it negatively influences the effort they put into their work, their organizational commitment, and their work-family enrichment. According to the results of this study, one could claim that the concept of alienation is a concept integral to organization studies. Other researches claim that the concept of alienation has the potential for helping understand why many contemporary teachers feel less engaged in or more dissatisfied with their job [9, 10, 15, 17, 24]. The findings of this study showed a statistically significant relationship between job alienation and job performance. In this sense, in different studies, diverse factors have been introduced that could influence the level of job alienation, including the impact of the rating source [25], managerial support [26], different tasks, and varied job descriptions [12], which could be regarded frustrating to many teachers. Alienation from school includes the feeling of unwillingness to take too much responsibility for school affairs, feeling uncomfortable at school, and having negative feelings about the teaching profession. One could claim when alienation occurs, problems between school management and teachers arise, which make teachers leave the decision-making process. While negative, moderate, and significant levels of relationship were detected between the quality of life and job alienation, low, negative, and significant levels of relationship were observed between the quality of life and school alienation [27]. The literature on work alienation has highlighted working environments that generate the sense of work alienation among employees and its negative effects on work-related attitudes, behaviors, and performance outcomes in many employees. Such environments could negatively affect employee engagement, organizational commitment, job satisfaction, well-being, work effort, and job efficiency [28].

Several studies show that a work environment in which altruism, collaboration, and duty prevail could have a positive impact on organizational performance and employees. Such an environment would motivate employees to sign an invisible contract with the organization, which indicates their happiness, belonging, and citizenship in all dimensions. Such conditions will increase their immunity to overcome the sense of work alienation [29]. This is based on our finding that when teachers feel disconnected from their jobs, it would have negative effects on the effort they put into their jobs, their organizational dedication, and work-family enrichment. According to the findings of this study, the idea of alienation remains an important topic in organizational studies [30]. Many studies suggest that the idea of alienation could help explain why teachers might feel less motivated or depressed about their job [31].

The insignificance of research in organizations in recent decades has made some respondents consider research useless. Teachers' concerns about the consequences of offering correct answers to questionnaire questions have made some of them avoid offering accurate answers to questionnaire questions. In this study, all responses were not complete despite necessary preparations, continuous follow-ups, and the time spent. Thus, it would be difficult to generalize the results by reducing the sample size.

A teacher in suitable financial, physical, and mental conditions will definitely focus more on educating and teaching students. In future research, it is suggested that the variables of job alienation and quality of life be compared with other variables, such as mental health, job stress, and so on. The sample was small for generalization, so it is recommended that a larger sample be selected in the future.

The present study demonstrated that job alienation could be a focal point of HR management scholars in the 21st century [13]. Taking into account the findings of this research and the factors identified as effective in job alienation, one could argue that the working conditions of teachers should be improved constantly. Since teachers are the main pillars of the education system and the most valuable capitals, some issues should be considered to reform the education system, including the role of HR, organizational justice, fair rewards, and progress possibilities at work. Moreover, benefits other than salaries, necessary instruments needed for doing work, appropriate facilities, hygiene, suitable environmental conditions, and more must be taken into account to avoid job alienation in teachers. Participation in organizational decisions, fair corporate accountability, safeguarding rights, job security, implementation of appropriate laws in organizations, and social values are among other factors to prevent job alienation in teachers [24].

\section{Conclusion}

Finally, it was found that the job alienation of teachers impacts job performance and quality of life. In this context, it can be suggested that working conditions should be constantly improved to increase the affective engagement of teachers and the conduct of organizational citizenship and 
reduce their level of job alienation in the schools for which they work.

\section{Acknowledgement}

The author (s) stated no potential conflicts of interest with respect to the research, authorship, and/or publication of this article

\section{Conflict of interest: None declared.}

\section{References}

1. Ali MR, Ashraf BN, Shuai C. Teachers' ConflictInducing Attitudes and Their Repercussions on Students' Psychological Health and Learning Outcomes. Int J Environ Res Public Health 2019; 16(14):2534.

2. Spilt JL, Koomen, HMY, Thijs JT. Teacher Wellbeing: The Importance of Teacher-Student Relationships. Educ Psychol Rev 2011; 23:45777.

3. Hackman JR, Oldham GR. Motivation through the design of work: test of a theory. Organ Behav Hum Perform 1976; 16(2):250-79.

4. Oldham GR, Hackman JR. Not what it was and not what it will be: the future of job design research. J Organ Behav 2010; 31(2-3):463-79.

5. Allan BA, Batz-Barbarich C, Sterling HM, Tay L. Outcomes of Meaningful Work: A MetaAnalysis. Journal of Management Studies 2019; 56(3):500-28.

6. Tulunay Ateş Ö, İhtiyaroğlu N. Analysis of the Relationship between Stress and Organizational Commitment in Employees: A Meta-Analysis Study. J Educ Train Stud 2019; 7(1):94-106.

7. Hoy WK, Blazovsky R, Newland W. Bureaucracy and alienation: A comparative analysis. The Journal of Educational Administration 1983; 21(2):109-21.

8. Çetinkanat AC, Kösterelioğlu MA. Relationship between Quality of Work Life and Work Alienation: Research on Teachers. Universal Journal of Educational Research 2016; 4(8):1778-86.

9. McKinlay JB, Marceau L. New wine in an old bottle: does alienation provide an explanation of the origins of physician discontent? Int $\mathrm{J}$ Health Serv 2011; 41(2):301-35.

10. Kurdi F. The Impact of Job Alienation on the Performance among Palestine Medical Complex Employees. International Humanities Studies 2018; 5(3):15-29.

11. Akar H. The Relationships between Quality of Work Life, School Alienation, Burnout, Affective Commitment and Organizational Citizenship: A Study on Teachers. European Journal of Educational Research 2018; 7(2):169-80.

12. Shantz A, Alfes K, Bailey C, Soane E. Drivers and Outcomes of Work Alienation: Reviving a Concept. Journal of Management Inquiry 2015; 24(4):382-93.
13. Shantz A, Alfes K, Truss C. Alienation from work: Marxist ideologies and twenty-first-century practice. The International Journal of Human Resource Management 2014; 25(18):2529-50.

14. Tajvaran M, Seif MH. The Causal Model of Work Alienation Based on the Quality of Work Life and Organizational Justic with an Emphasis on the Mediating Role of Conflict, Organizational Commitment and Job Involvement among Physical Education Teachers in Shiraz City. Sport Management Studies 2017; 9(43):61-80.

15. Özer Ö, Uğurluoğlu Ö, Saygılı $M$, Sonğur C. The impact of work alienation on organizational health: A field study in health sector. Int $\mathrm{J}$ Healthc Manag 2019; 12(1):18-24.

16. Golden TD, Veiga JF. Self-Estrangement's Toll on Job Performance: The Pivotal Role of Social Exchange Relationships with Coworkers. Journal of Management 2015; 44(4):1573-97.

17. Tummers LG, Den Dulk $L$. The effects of work alienation on organizational commitment, work effort and work-to-family enrichment. J Nurs Manag 2013; 21(6):850-9.

18. Mottaz CJ. Some Determinants of Work Alienation. Sociol Q 1981; 22(4):515-29.

19. Nadi MA, Alsafi MA. The mediation role of work alienation dimensions on the relationship between person-organization fit and organizational citizenship behaviors. Contemporary Psychology 2014; 8(2):81-94.

20. Peterson SJ, Byron K. Exploring the role of hope in job performance: results from four studies. J Organ Behav 2008; 29(6):785-803.

21. Khandan M, Eyni Z, Koohpaei A. Relationship between Spiritual Intelligence and Job Performance: A Case Study of Nurses and Nursing Aids in the Main University Hospital of Qom, Iran. Health Spirituality and Medical Ethics 2017; 4(3):8-13.

22. Ware JE Jr, Sherbourne CD. The MOS 36 -item short-form health survey (SF-36). I. Conceptual framework and item selection. Med Care 1992; 30(6):473-83.

23. Asghari Moghaddam M, Faghehi S. Validity of the SF-36 Health Survey Questionnaire in Two Iranian Samples. Clinical Psychology \& Personality 2003; 1(1):1-10.

24. Nojabaee SS, Ahmadi Gh. Identification of Factors Affecting Teachers' Job Alienation in Western Mazandaran Province. Journal of Applied Environmental and Biological Sciences 2014; 4(7):136-43.

25. Clark SK, Halbesleben JRB, Lester SW, Heintz R. Temporary Worker Alienation and Job Performance: The Impact of Rating Source. J Leadersh Organ Stud 2010; 17(3):287-97.

26. Tummers L, den Dulk L. Meaningful work for a meaningful life? Work alienation and its effects in the work and the family context. Paper presented at: The Human resources management in Volatile Times: the paradoxical challenges facing Human. Rotterdam, 
Netherlands: Erasmus University Rotterdam; 2012.

27. Tummers LG, Knies E. Leadership and Meaningful Work in the Public Sector. Public Adm Rev 2013; 73(6):859-68.

28. Khan MAS, Jianguo D, Mann A, Saleem $S$, Boamah KB, Javed $U$, et al. Rejuvenating the Concept of Work Alienation through Job Demands-Resources Model and Examining Its Relationship with Emotional Exhaustion and Explorative and Exploitative Learning. Psychol Res Behav Manag 2019; 12:931-41.

29. Kocoglu Sazkaya M. Cynicism as a mediator of relations between job stress and work alienation: a study from a developing countryTurkey. Global Business and Management Research 2014; 6(1):24-36.

30. Tummers LG, Den Dulk L. The effects of work alienation on organisational commitment, work effort and work-to-family enrichment. J Nurs Manag 2013; 21(6):850-9.

31. McKinlay JB, Marceau L. New wine in an old bottle: does alienation provide an explanation of the origins of physician discontent? Int $\mathrm{J}$ Health Serv 2011; 41(2):301-35. 